\title{
Topological mapping of the P1-adhesin of Mycoplasma pneumoniae with adherence-inhibiting monoclonal antibodies
}

\author{
B. GersteneCKer and E. JACOBs* \\ Department for Microbiology and Hygiene, Institute for Medical Microbiology and Hygiene, Hermann Herder Str. 11, \\ D-7800 Freiburg FRG
}

(Received 22 August 1989; revised 27 October 1989; accepted 9 November 1989)

\begin{abstract}
Five adherence-inhibiting monoclonal antibodies (mAbs) were used for topological mapping of the binding sites of the $169 \mathrm{kDa}$ membrane-integrated adhesin of Mycoplasma pneumoniae. Antibody binding sites were characterized using overlapping synthetic octapeptides. Three regions of the protein seem to be involved in adherence: the $\mathrm{N}$ terminal region [N-reg, epitopes beginning at amino acid (aa) 1 to aa 14 and aa 231 to aa 238, respectivelyl; a domain (B1) approximately in the middle of the molecule (beginning at aa 851 to aa 858 and aa 921 to aa 928); and a domain (D2) closer to the C-terminus (beginning at aa 1303 to aa 1310, aa 1391 to aa 1398 and aa 1407 to aa 1414). Each of the mAbs P1.26 and P1.62 reacted with two primary amino acid sequences. Both antibodies bound to the D1 region, but mAb P1.62 showed additional binding to a sequence (aa.231 to aa 238) near the Nterminus, and $m A b$ P1.26 reacted with a second epitope in the D2 domain (aa 1303 to aa 1310). Such dual binding by the two antibodies suggests that in the native protein the epitopes are composed of two sequences which are located on two different sites of the molecule (D1/N-reg and D1/D2, respectively). In a competitive ELISA test using native $M$. pneumoniae cells as antigen, both the mAb directed to the $\mathrm{N}$-terminus (aa 1 to aa 14) and mAbs directed to those epitopes nearest to the $C$-terminus (aa 1391 to aa 1398 and aa 1407 to aa 1414) were able to prevent binding of mAbs P1.26 and P1.62 to the native cells. The results of epitope mapping and inhibition tests suggest a close spatial relationship of the domains N-reg, D1 and D2 in forming a functionally active adherence binding site. Furthermore, the outermost epitopes of the domains involved seem to be located on top of folded loops of the protein molecule.
\end{abstract}

\section{Introduction}

The human respiratory pathogen Mycoplasma pneumoniae adheres strongly to erythrocytes (Feldner et al., 1979; Baseman et al., 1982), hamster tracheal cells (Hu et al., 1976; Gabridge et al., 1978) and human lung fibroblasts (Gabridge et al., 1979). The major adhesin mediating contact to these cells (P1-protein) is concentrated at the tip-like structure of the organism ( $\mathrm{Hu}$ et al., 1982; Feldner et al., 1982). Monoclonal antibodies (mAbs) binding to the P1-protein inhibit the attachment of the pathogen to red blood cells and hamster tracheal cells (Hu et al., 1982; Morrison-Plummer et al., 1986). The mature P1-adhesin consists of 1567 amino acids (Jacobs et al., 1987; Dallo et al., 1988; Inamine et al., 1988). One of the primary sequences of the adherence-mediating regions has been located near to the C-terminus by screening a recombinant DNA expression library of $M$.

Abbreviations: aa, amino acid; mAb, monoclonal antibody; TFA, trifluoroacetic acid. pneumoniae with an anti-P1 adherence-inhibiting mAb (Dallo et al., 1988). Using peptide patterns of cyanogenbromide-cleaved P1-protein we recently found two additional and different binding sites of adherenceinhibiting $\mathrm{mAbs}$. One is located near the $\mathrm{N}$-terminus and the other approximately in the middle of the amino acid sequence (Jacobs et al:, 1989). From these results, we speculated that the native attachment structure might be composed of several surface-exposed loops. To obtain further information on the topographical arrangement we used two adherence-inhibiting $\mathrm{mAbs}$ which bound to two epitopes, each on separate domains. The results of inhibition studies with these and other adherenceinhibiting $\mathrm{mAbs}$ are reported here and their implications are discussed.

\section{Methods}

Peptide synthesis. Solid-phase peptide synthesis based on the use of $N^{a}$-(9-fluorenylmethyloxycarbonyl) (FMOC) amino acids (Dryland \& 
Sheppard, 1986; Sheppard, 1986) was used for the preparation of synthetic antigens. The peptides were synthesized in two different ways: (i) for the production of adequate amounts of the synthetic $\mathrm{N}$ terminus, a semi-automatic peptide synthesizer (Biolynx 4175; Pharmacia/LKB) was used; (ii) the epitope scanning kit (CRB) producing overlapping synthetic octapeptides was used according to the method of Geysen $e t$ al. (1984) for analysis of the mAb binding sites within the preselected P1-protein regions N-reg (aa 172 to aa 343), D1 (aa 841 to aa 941) (Jacobs et al., 1989) and D2 (aa 1241 to aa 1441) (Dallo et al., 1988).

The column-synthesized N-terminus of the mature P1-protein was cleaved from the resin (Ultrosyn A; Pharmacia/LKB) by treatment with $95 \%(v / v)$ trifluoroacetic acid. The released peptide was precipitated and washed repeatedly with diethyl ether. The raw peptide preparation was dried, and purified by HPLC using a reverse-phase column (TSK ODS-120T, $\mathrm{C}_{18}, 5 \mu \mathrm{m}, 4.6 \times 250 \mathrm{~mm}$; LKB). A linear gradient $\left(0.6 \% \mathrm{~B} \mathrm{~min}^{-1}\right)$ was applied [eluant A, $0.1 \%$ TFA; eluant B, acetonitrile/water $(80: 20, \mathrm{v} / \mathrm{v}) \quad 0.08 \%$ TFA] flow rate $1 \mathrm{ml} \mathrm{min}^{-1}$. The eluate was monitored at $215 \mathrm{~nm}$. The homogeneous peptide peak fractions were pooled and dried using a 'Speed-vac' centrifuge. The pin-immobilized overlapping peptides were acetylated with acetic anhydride, the side-chain protecting groups were cleaved and, after extensive washing, the peptides, still bound to the solid phase, were dried according to the manufacturer's (Cambridge Research Biochemicals) recommendations.

Preparation of adherence-inhibiting mAbs. Two different antigens were used for immunization: (i) viable glass-adherent $\boldsymbol{M}$. pneumoniae cells (strain FH) cultured in Hayflick's modification of Edward's medium (Hayflick, 1965); (ii) isolated and purified P1-adhesin (Jacobs et al., 1988). Two 3-month-old male Balb/c mice were injected intraperitoneally with freshly harvested mycoplasma cells (1 mg total protein per injection) or isolated P1-protein (Jacobs et al., 1988; $100 \mu \mathrm{g}$ per injection). The antigens were used without any adjuvant. The immunizations (intraperitoneal) were repeated four times at weekly intervals and 3 to $4 \mathrm{~d}$ before spleen cells were removed at post mortem for fusion. The somatic-cell fusion with X63-Ag8.653 myeloma cells was done according to the method of De St Groth \& Scheidegger (1980). Several hundred viable hybridoma clones were recovered from both fusions. The secreted antibodies were screened for: (i) recognition of the P1-protein and sonicated mycoplasma cells in ELISA systems (Jacobs et al., 1986); (ii) binding to the denatured and electroblotted P1-protein using Western immunoblotting (Towbin et al., 1979); (iii) inihibition of adherence of sheep red blood cells to mycoplasmas (Jacobs et al., 1985); and (iv) binding to the tip-structure of the organism in an immunofluorescence test using glass-adherent native mycoplasmas (Feldner et al. 1982). The appropriate hybridomas were cloned by using a limiting-dilution technique. Two clones of the anti-P1 fusion [P1 .26 and P1.62(F2); Jacobs et al., 1989] and two clones of the anti-mycoplasma fusion (M51 and M58) fulfilled the requirements mentioned above and were cultured in vivo in mice for ascites production.

For the preparation of site-specific mAbs the synthetic $\mathrm{N}$-terminus of the mature P1-protein was cleaved from the synthesizer resin and purified by HPLC. The oligopeptide was used in free form for the immunization of Balb/c mice (Atassi, 1986). The mice were immunized with $100 \mu \mathrm{g}$ purified peptide, injected intraperitoneally together with an aluminium hydroxide adjuvant (Alu-Gel-S; Serva). Four injections were given at monthly intervals. Somatic-cell fusion was done as described above. Twenty-two antibody-producing hybridomas survived the selection. The antibodies were screened for binding to the homologous peptide and were tested for activity in the various assays described above.

Epitope mapping with overlapping peptides. Ascites fluids from the different hybridoma clones were diluted in blocking buffer [1\% BSA,
$1 \%$ ovalbumin, $1 \%$ Tween 20 in PBS (0.14 M- $\mathrm{NaCl}, 0.01 \mathrm{M}$-sodium phosphate, $\mathrm{pH} 7 \cdot 2)$, and incubated overnight with the pre-blocked solid-phase (pin)-immobilized octapeptides at $4{ }^{\circ} \mathrm{C}$. The peptide-pins were washed with PBS/Tween 20 and incubated with an alkalinephosphatase-conjugated secondary antibody (goat anti-mouse immunoglobulins; Dianova, FRG) diluted in blocking buffer. After the final washing, the pins were incubated in substrate solution $\left(10 \mathrm{mg} \mathrm{ml}^{-1} p\right.$ nitrophenyl phosphate in diethanolamine buffer, $\mathrm{pH} \mathrm{9.6)} \mathrm{for} 1 \mathrm{~h}$ at $37^{\circ} \mathrm{C}$. The $A_{405}$ was determined with a Titertek Multiscan.

Competition ELISA. M. pneumoniae cells were cultured in Roux flasks with Hayflick's modification of Edward's medium (Hayflick, 1965) for $48 \mathrm{~h}$ at $37^{\circ} \mathrm{C}$. Glass-adherent cells were scraped off and washed with PBS. The cell suspension was adjusted to a protein concentration of $100 \mu \mathrm{g} \mathrm{ml}^{-1}$ determined according to the method of Peterson (1977). Microtitre plates were pretreated with poly(L-lysine) $(50 \mu \mathrm{g}$ per well) and glutaraldehyde $(100 \mu \mathrm{l}$ of a $20 \%$, v/v, solution in deionized water) (McEachran \& Irvin, 1986). Samples $(100 \mu 1)$ of the cell suspension were incubated on these microtitre plates for $2 \mathrm{~h}$ at $37^{\circ} \mathrm{C}$ under gentle rotation. The plates were washed with pre-warmed PBS and remaining aldehyde groups were blocked with $3 \%$ BSA/PBS for $1 \mathrm{~h}$ at $37^{\circ} \mathrm{C}$. Unlabelled $\mathrm{mAb}(100 \mu \mathrm{l}$ per well) was added and incubated for $2 \mathrm{~h}$ at $37^{\circ} \mathrm{C}$ under maximum antigen saturation conditions (the relative $\mathrm{mAb}$ concentration that is necessary to block all accessible binding sites). Biotin-labelled mAb ( $500 \mathrm{ng}$ in $20 \mu \mathrm{l}$ per well) was then added without washing and further incubated for $1 \mathrm{~h}$ at $37^{\circ} \mathrm{C}$ (Jackson et al., 1982; Stähli et al., 1983). The plates were washed three times with PBS $/ 0.05 \%$ Tween 20 . The binding of the biotin-labelled $\mathrm{mAb}$ was detected with streptavidin/peroxidase (Sigma; $200 \mathrm{ng}$ per well). Substrate $\left(\mathrm{H}_{2} \mathrm{O}_{2}\right.$ / tetramethylbenzidine) was added and the colour development was measured as the $\boldsymbol{A}_{450}$ after $30 \mathrm{~min}$ incubation at room temperature.

\section{Results}

\section{Screening for adherence-inhibiting $m A b s$}

Two out of 300 hybridomas from fusion experiments with viable $M$. pneumoniae cells (M51 and M58) and two out of $\mathbf{8 0 0}$ hybridomas from the P1-protein immunization (P1.26 and P1.62) showed adherence-inhibiting activity. These mAbs also recognized isolated P1-protein and sonicated mycoplasma cells as antigen in ELISA tests. Additionally, they showed binding to the P1protein in Western immunoblots. In the immunofluorescence test with native organisms, these $\mathrm{mAbs}$ gave distinct fluorescence located at the tip-like structure of the mycoplasmas, indicating P1-specificity on intact cells. Anti-peptide $\mathrm{mAb}$ aN was specific for the homologous peptide and also showed fluorescence on the tip-structure of $M$. pneumoniae, indicating a cell-surface location of the $\mathrm{N}$-terminus (aa 1 to aa 14) of the mature membrane-integrated P1-protein. mAb aN strongly inhibited the adherence of sheep red blood cells to $M$. pneumoniae.

\section{Epitope mapping with overlapping synthetic peptides}

The adherence-inhibiting $\mathrm{mAbs}$ were tested for binding to overlapping octapeptides mimicking three regions of 


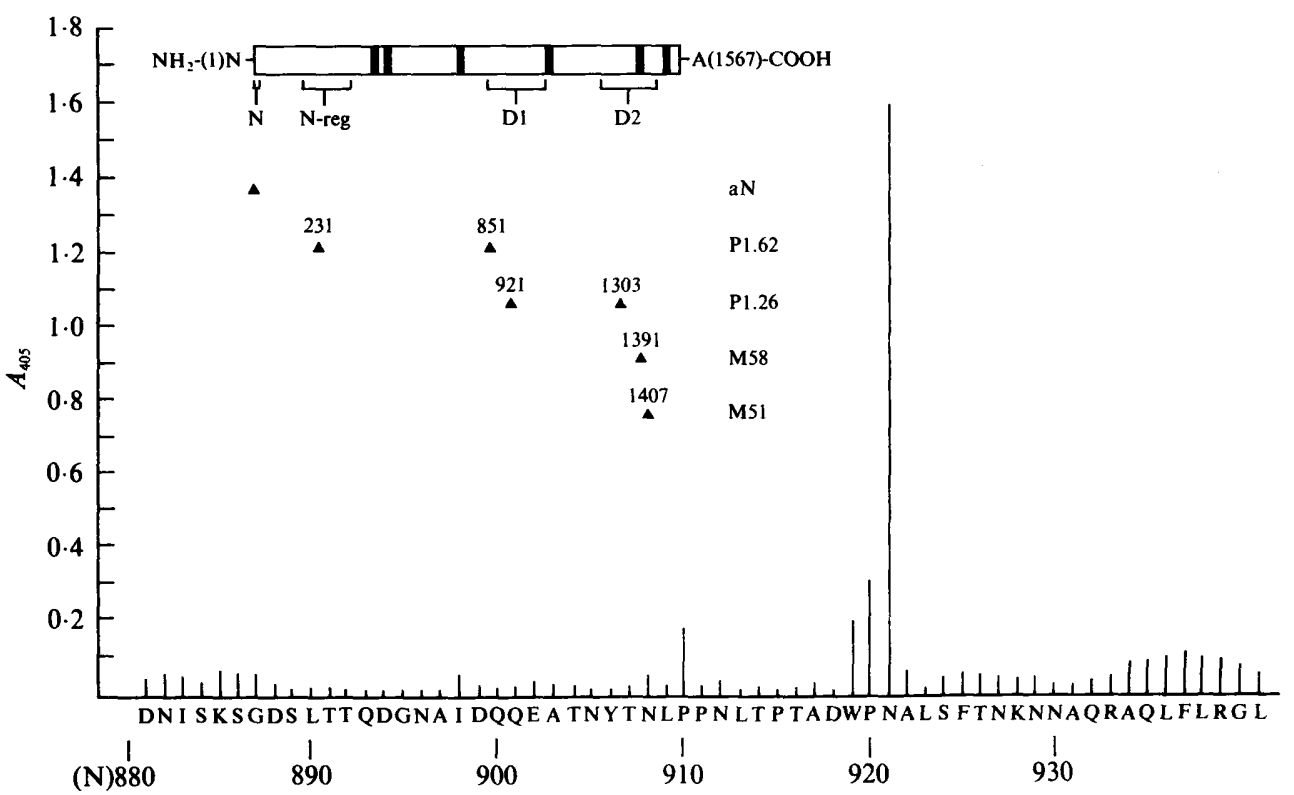

Fig. 1. ELISA activity of the mAb P1.26 (ascites) with synthetic, overlapping solid-phase octapeptides of the amino acid sequence of domain D1 (aa 841 to aa 1011). The insert shows the binding sites for the different $m A$ bs within the primary amino acid sequence of the mature P1-protein. For mAb aN the location of the synthetic antigen used for immunization is shown. The epitopes of the mAbs resulted from peptide-ELISA experiments. The solid areas indicate predicted membrane-associated helices according to Eisenberg $e t$ al. (1984).

the mature P1-protein: (i) the N-terminal region (Thr173 to Tyr-344); (ii) domain D1 (Asn-841 to Arg-1011); and (iii) domain D2 (Asn-1241 to Pro-1441).

An example of an antigenic profile resulting from the peptide-ELISA is shown for $\mathrm{mAb} P 1.26\left(\operatorname{IgG}_{1} \kappa\right)$ with domain D1 (Fig. 1). The antibody activity is clearly limited to one peptide in D1 [ $\mathrm{NH}_{2}-(921)-\mathrm{N}-\mathrm{A}-\mathrm{L}-\mathrm{S}-\mathrm{F}-\mathrm{T}-$ $\mathrm{N}-\mathrm{K}$ ]. The same antibody also binds to a peptide sequence in domain D2 [ $\mathrm{NH}_{2}-(1303)-D-V-V-G-V-G-R-$ L]. The $\mathrm{mAb} P 1.62\left(\mathrm{IgG}_{1} \kappa\right)$ binds to the sequence $\mathrm{NH}_{2-}^{-}$ (851)-E-N-H-T-K-F-T-S in D1 and to the octapeptide $\mathrm{NH}_{2}$-(231)-E-V-K-K-K-S-D-S in the N-terminal region. mAbs $M 58\left(\operatorname{IgG}_{1} \kappa\right)$ and M51 $\left(\operatorname{IgG}_{2 \mathrm{~b}} \kappa\right)$ showed binding to D2 on $\mathrm{NH}_{2}-(1391)-\mathrm{S}-\mathrm{V}-\mathrm{N}-\mathrm{P}-\mathrm{K}-\mathrm{M}-\mathrm{V}-\mathrm{R}$ and $\mathrm{NH}_{\mathbf{2}^{-}}$ (1407)-N-E-Q-S-L-G-L-R respectively.

Anti-peptide $\mathrm{mAb}$ aN $\left(\mathrm{IgG}_{1} \kappa\right)$, which is directed against the synthetic $\mathrm{N}$-terminus of the mature P1protein, also showed strong adherence-inhibiting activity but possessed no antigenic site in D1 and D2 when tested with these short linear peptides.

\section{Competition-ELISA}

To investigate the epitopes for the different $\mathrm{mAbs}$ with regard to the native conformation of the P1-adhesin, a competitive ELISA was done. The results are shown in Table 1. The dilution of the pre-incubated $\mathrm{mAb}$ (ascites fluid) was pre-tested for maximal competition with the
Table 1. Competitive ELISA for epitope mapping of the $P$ l-protein adherence structure using viable $M$. pneumoniae cells and adherence-inhibiting $m A b s$

Inhibition (I) was defined arbitrarily as follows: $I \leqslant 20 \%$, no inhibition (0); I 21 to $50 \%$, partial inhibition $(+/-)$; I $>50 \%$, inhibition $(+)$. Undisturbed binding of each $\mathrm{mAb}$ was used as a non-competition control, and is defined as having $100 \%$ binding efficiency and producing $0 \%$ inhibition. The test included selfcompetition controls.

Inhibition of probed biotin-labelled $\mathrm{mAb}$

\begin{tabular}{lccccc}
\cline { 2 - 5 } Pre-incubation with mAb & aN & P1.62 & P1.26 & M51 & M58 \\
\hline aN (N-term) & + & + & + & $+/-$ & + \\
P1.62 (N-reg/D1) & 0 & + & + & 0 & 0 \\
P1.26 (D1/D2) & 0 & $+1-$ & + & 0 & 0 \\
M51 (D2) & 0 & + & + & + & 0 \\
M58 (D2) & $+/-$ & + & + & $+/-$ & + \\
\hline
\end{tabular}

homologous $\mathrm{mAb}$ in the ELISA (mAb dilutions ranged from $1: 10$ to $1: 200$ ). The assay also included noncompetitive controls: each biotinylated $\mathrm{mAb}$ was analysed for binding without pre-incubation of unlabelled antibodies. The preincubated $\mathrm{mAbs}$ aN (aa 1 to aa 14) and M58 (anti-D2, aa 1391 to aa 1398) inhibited binding of all other mAbs totally or partially, but were inhibited only by each other. mAb M51 (anti-D2, aa 1407 to aa 1413) interfered with binding of $\mathrm{mAb} P 1.26$ (anti-D1, aa 921 to aa 928; anti-D2, aa 1303 to aa 1310) and $\mathrm{mAb}$ 
P1.62 (anti-N-terminal region, aa 231 to aa 238 ; antiD1, aa 851 to aa 858), but was itself inhibited only by $\mathrm{mAbs} \mathrm{aN}$ and M58. The mAbs P1.26 and P1.62 were inhibited by all other antibodies. In pre-incubation, these two mAbs inhibited only each other.

\section{Discussion}

The results suggest that at least three regions of the P1protein are necessary to build the tertiary structure that mediates adherence of $M$. pneumoniae to host cells. Recently, Dallo et al. (1988) reported an amino acid sequence, $\mathrm{NH}_{2}$-(1324)-G-I-V-R-T-P-L-A-E-L-L-D-G, which showed binding activity with an adherenceinhibiting $\mathrm{mAb}$. This sequence is positioned between the epitopes of our adherence-inhibiting $\mathrm{mAbs} P 1.26\left[\mathrm{NH}_{2^{-}}\right.$ (1303)-D-V-V-G-V-G-R-L] and M58 [ $\mathrm{NH}_{2}-(1391)-\mathrm{S}-\mathrm{V}-$ N-P-K-U-V-R] of the D2-binding site. At least two other quite different regions of this high-molecular-mass protein are involved in the adherence mechanism. Using cyanogen bromide fragments of the P1-protein and mAbs, we recently described antigenic regions near the $\mathrm{N}$-terminus (beginning with the amino acid phenylalanine-177) and another region located approximately within the middle of the P1-protein (D1 region: beginning with the amino acid tryptophan-642) (Jacobs et al., 1989). Testing overlapping peptides in an ELISA, the binding sites of the two mAbs P1.62 and P1.26 have now been identified precisely. Interestingly, both antibodies each reacted with two epitopes: mAb P1.26 bound to D1 and D2 and mAb P1.62 to N-reg and D1.

All three domains (N-reg, D1 and D2 region) are defined by the following computer-predicted membraneassociated helices (see Fig. 1): (i) N-reg to D1 by three hydrophobic sequences, aa 421 to aa 447 , aa 471 to aa 491 and aa 733 to aa 753; (ii) D1 and D2 by the predicted helix aa 1047 to aa 1066 .

Berzofsky \& Schechter (1981) and Atassi (1984) showed that antigenic sites of proteins are mainly composed of separated primary sequences brought together by protein-folding in the native state, thus forming a discontinuous functionally active site. This process might also be responsible for the dual binding sites of the mAbs P1.26 and P1.62.

The results of the epitope mapping and of the inhibition studies elucidate some aspects of the topology of the (functionally active) adherence binding site. The close association of the domains D1 with D2, on one hand, and of D1 with $\mathrm{N}$-reg, on the other, is suggested by the dual binding of the mAbs P1.26 and P1.62, respectively. Additional information is given by the inhibition tests with native P1-protein of living $M$. pneumoniae cells. Antibodies against two regions [N-term

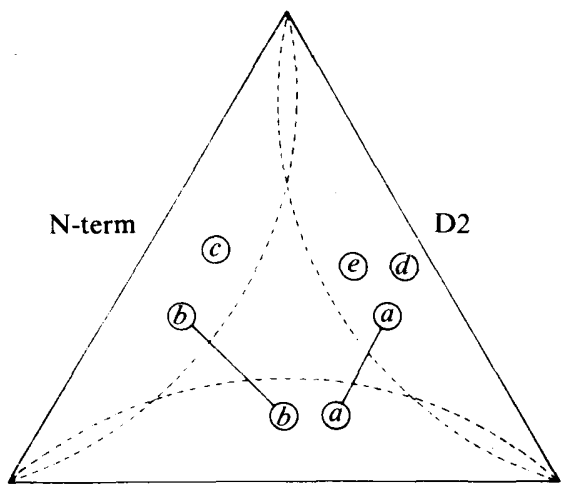

Dl

Fig. 2. Possible topographical arrangement of the adherence-mediating binding sites of the P1-protein of $M$. pneumoniae. The binding sites of the adherence-inhibiting mAbs (Fig. 1) and the results of the competitive ELISA (Table 1) show a close relationship between D1 (located near the middle of the protein) and D2 (located near the Cterminus) and of the $\mathrm{N}$-terminal region with both $\mathrm{D} 1$ and $\mathrm{D} 2$ as a result of the competition patterns of the mAbs P1.26 (a), P1.62(b), aN (c), M51 (d) and M58 (e).

(aa 1 to aa 14) and D2 (aa 1391 to aa 1398)] were able to prevent the binding of $\mathrm{mAbs}$ to the other five epitopes. This effect can be interpreted in different ways. (i) $\mathrm{mAb}$ M58 and mAb aN binding sites could be located at the top of surface-exposed protein loops, whereas binding sites of $\mathrm{mAb} P 1.26$ and $\mathrm{P} 1.62$ are positioned in a depression of the surface of the folded protein. Therefore, it is possible that mAb M58 and mAb aN could block the entrance of the other three mAbs. (ii) Binding of antibody mAb aN amd mAb M58 could also provoke conformational changes within the tertiary structure (Guirakhoo et al., 1989), so that the two binding sites of mAbs P1.26 and P1.62 are no longer surface exposed. (iii) Stone \& Nowinski (1980) discussed a third possibility: after monovalent binding of IgG antibodies to a molecule, a considerable amount of molecular rotational freedom is retained, which might also disturb the binding of mAbs P1.26 and P1.62.

The reciprocal inhibition of the mAbs P1.62 (N$\mathrm{reg} / \mathrm{D} 1)$ and $\mathrm{P} 1.26$ (D1/D2) suggests a close association of these sites. The inhibition could be caused by steric competition for the limited space available within the suggested surface depression of the protein, rather than by the closeness of the different epitopes. Pre-incubation with $\mathrm{mAb}$ aN also blocked mAb M51 and mAb M58 binding. Pre-incubation with mAb M58 was able partially to block the mAb aN, whereas mAb M51 did not affect binding of $\mathrm{mAb} \mathrm{aN}$. These findings suggest not only that the D1 domain is located near the $\mathrm{N}$ terminal region and the $\mathrm{D} 2$ domain, but also that the $\mathrm{N}$ terminal region must be in close contact with the D2 region. In this hypothetical arrangement, at least three 
different loops are brought together by protein folding in the native P1-protein (Fig. 2).

Apparently, the adherence mechanism of M. pneumoniae to target cells is more complicated than first experiments suggested (Inamine et al., 1988). The data support the idea of a three-dimensional arrangement of different P1-membrane protein segments necessary to form an effective adherence structure. Whether this arrangement exists permanently on the native protein or is only formed after contact with receptor structures is as yet unknown. The requirement for energy for adherence to surfaces (Feldner et al., 1981), and the lack of binding at $4{ }^{\circ} \mathrm{C}$ (Feldner et al., 1979) could be taken as support for the latter possibility.

Furthermore, it is not known whether the interaction between binding site and receptors is dependent more on variable factors, such as charge patterns and hydrophobic interactions, or on defined amino acid sequences of the P1-protein with carbohydrate receptors on the host cells. The variety of receptors described in the literature (Gabridge et al., 1978, 1979; Geary \& Gabridge, 1987; Loomes et al., 1985) suggests to some extent an involvement of the flexible mechanisms mentioned above. In this way, the binding sites of the extracellular parasite $M$. pneumoniae could adapt themselves to the various structures of the host cells of the respiratory tract.

\section{References}

ATAssi, M. Z. (1984). Antigenic structures of proteins. European Journal of Biochemistry 145, 1-20.

AtAssi, M. Z. (1986). Preparation of monoclonal antibodies to preselected protein regions. Methods in Enzymology 121, 69-95.

Baseman, J. B., Banal, M. \& KahANe, I. (1982). Sialic acid residues mediate Mycoplasma pneumoniae attachment to human and sheep erythrocytes. Infection and Immunity 38, 389-391.

BERZOPSKY, J. A. \& SCHECHTER, A. N. (1981). The concepts of crossreactivity and specificity in immunology. Molecular Immuno$\log y 18,751-763$.

Dallo, S. F., Su, C. J., Horton, J. R. \& Baseman, J. B. (1988). Identification of $\mathrm{Pl}$ gene domain containing epitope(s) mediating Mycoplasma pneumoniae cytadherence. Journal of Experimental Medicine 167, 718-723.

De St Groth, F. S. \& Scheidegger, D. (1980). Production of monoclonal antibodies: strategy and tactics. Journal of Immunological Methods 35, 1-21.

DrYland, A. \& ShepPard, R. C. (1986). Peptide synthesis. 8. A system for solid-phase synthesis under low pressure continuous flow conditions. Journal of the Chemical Society Perkin-Transactions I, 125-137.

Eisenberg, D., Schwarz, E., Komaromy, M. \& Wall, R. (1984). Analysis of membrane and surface protein sequences with the hydrophobic moment plot. Journal of Molecular Biology 179, 125142.

FeldNer, J., BREDT, W. \& KaHANE, I. (1979). Adherence of erythrocytes to Mycoplasma pneumoniae. Infection and Immunity 25, $60-67$.

FELDNER, J., BREDT, W. \& RAzIN, S. (1981). Role of energy metabolism in Mycoplasma pneumoniae attachment to glass surfaces. Infection and Immunity 31, 107-113.
FeLdNER, J., Göbel, U. \& BREDT, W. (1982). Mycoplasma pneumoniae adhesin localized to tip structure by monoclonal antibody. Nature, London 298, 765-767.

GABRIDGe, M. G., Gunderson, H., Schaepfer, S. L \& DeE BARDENSTAHL, Y. (1978). Ciliated respiratory epithelial monolayers: new model for Mycoplasma pneumoniae infection. Infection and Immunity 21, 333-336.

Gabridge, M. G., Taylor-Robinson, D., Davies, H. A. \& DourMASHKIN, R. (1979). Interaction of Mycoplasma pneumoniae with human lung fibroblasts: characterization of the in vitro model. Infection and Immunity 25, 446-454.

GEARY, S. J. \& GABRIDGE, M. G. (1987). Characterization of a human lung fibroblast receptor site for Mycoplasma pneumoniae. Israel Journal of Medical Sciences 23, 462-468.

Geysen, H. M., Meloen, R. H. \& Barteling, S. J. (1984). Use of peptide synthesis to probe viral antigens for epitopes to a resolution of a single amino acid. Proceedings of the National Academy of Sciences of the United States of America 81, 3998-4002.

GUIRAKHOO, F., HeINZ, F. R. \& KUNZ, C. (1989). Epitope model of thick-borne encephalitis virus envelope glycoprotein $E$ : analysis of structural properties, role of carbohydrate side chains, and conformational changes occurring at acidic pH. Virology 169, 90-99.

HAYPLICK, L. (1965). Tissue cultures and mycoplasmas. Texas Reports on Biology and Medicine 23, 285-303.

Hu, P. C., Collier, A. M. \& Baseman, J. B. (1976). Interaction of virulent Mycoplasma pneumoniae with hamster tracheal organ cultures. Infection and Immunity 14, 217-224.

Hu, P. C., Cole, R. M., Huang, Y. S., Graham, J. A., Gardner, D. E., COLLIER, A. M. \& CLYDE, W. A. (1982). Mycoplasma pneumoniae infection: role of a surface protein in the attachment organelle. Science 216, 313-315.

InAMine, M. J., DenNy, T. P., Loechel, S., SChPAPER, M., Huang, C. H., BoTT, K. F. \& HU, P. C. (1988). Nucleotide sequence of the PIattachment protein gene of Mycoplasma pneumoniae. Gene 64, 217229.

JACKSON, S., SOGN, J. \& KINDT, T. (1982). Microdetermination of rabbit immunoglobulin allotypes by ELISA using specific antibodies conjugated with peroxidase or with biotin. Journal of Immunological Methods 48, 299-309.

JACOBS, E., SCHÖPPERLE, K. \& BREDT, W. (1985). Adherence inhibition assay: a specific serological test for detection of antibodies to Mycoplasma pneumoniae. European Journal of Clinical Microbiology 4, 113-118.

JACOBS, E., FUCHTE, K. \& BREDT, W. (1986). A $168 \mathrm{kDa}$ protein of Mycoplasma pneumoniae used as antigen in a dot enzyme-linked immunosorbent assay. European Journal of Clinical Microbiology 5 , 435-440.

JACOBS, E., FUCHTE, K. \& BREDT, W. (1987). Amino acid sequence and antigenicity of the amino-terminus of the $168 \mathrm{kDa}$ adherence protein of Mycoplasma pneumoniae. Journal of General Microbiology 133, 2233-2236.

JACOBS, E., FUCHTE, K. \& BREDT, W. (1988). Isolation of the adherence protein of Mycoplasma pneumoniae by fractioned solubilization and size exclusion chromatography. Biological Chemistry Hoppe-Seyler 369, $1295-1299$.

Jacobs, E., Gerstenecker, B., Mader, B., Huang, C.-H., Hu, P. C., HALTER, R. \& BREDT, W. (1989). Binding sites of attachmentinhibiting monoclonal antibodies and antibodies from patients on peptide fragments of the Mycoplasma pneumoniae adhesin. Infection and Immunity 57, 685-688.

LOOMES, L. M., UemuRA, K. \& FeIZI, T. (1985). Interaction of Mycoplasma pneumoniae with erythrocyte glycolipids of $\mathrm{I}$ and $\mathrm{i}$ antigen types. Infection and Immunity 47, 15-20.

MCEACHRAN, D. W. \& IRVIN, R. T. (1986). A new method for the irreversible attachment of cells or proteins to polystyrene tissue culture plates for use in the study of bacterial adhesion. Journal of Microbiological Methods 5, 99-111.

Morrison-Plummer, J., Leith, D. K. \& Baseman, J. B. (1986). Biological effects to anti-lipid and anti-protein monoclonal antibodies on Mycoplasma pneumoniae. Infection and Immunity 53, 398403. 
Petreson, G. L. (1977). A simplification of the protein assay method of Lowry et al. which is more generally applicable. Analytical Biochemistry 83, 346-356.

SHEPPARD, R. C. (1986). Modern methods of solid-phase peptide synthesis. Science Tools 33, 9-16.

Stähli, C., Miggiano, V., Stocker, J., Staehelin, T., Häring, P. \& TAKACS, B. (1983). Distinction of epitopes by monoclonal antibodies. Methods in Enzymology 92, 242-253.
STONE, M. R. \& Nowinski, R. C. (1980). Topological mapping of murine leukemia virus proteins by competition binding assay with monoclonal antibodies. Virology 100, 370-381.

Towbin, H., Staehelin, T. \& Gordon, J. (1979). Electrophoretic transfer of proteins from polyacrylamide gels to nitrocellulose sheets: procedure and some applications. Proceedings of the National Academy of Sciences of the United States of America 76, 4350-4354. 